\title{
Laparoscopic versus robotic-assisted, left-sided colectomies: intra- and postoperative outcomes of 683 patients
}

\author{
Jörn-Markus Gass, ${ }^{1,2}$ - Diana Daume ${ }^{3} \cdot$ Romano Schneider $^{3} \cdot$ Daniel Steinemann $^{3} \cdot$ Francesco Mongelli $^{4}$. \\ Andreas Scheiwiller ${ }^{1}$ - Lana Fourie ${ }^{3} \cdot$ Beatrice Kern $^{3} \cdot$ Markus von Flüe $^{3} \cdot$ Jürg Metzger $^{1} \cdot$ Fiorenzo Angehrn $^{3}$. \\ Martin Bolli ${ }^{3}$
}

Received: 31 July 2021 / Accepted: 31 December 2021 / Published online: 13 January 2022

(c) The Author(s) 2022

\begin{abstract}
Background Robotic-assisted colorectal surgery has gained more and more popularity over the last years. It seems to be advantageous to laparoscopic surgery in selected situations, especially in confined regions like a narrow male pelvis in rectal surgery. Whether robotic-assisted, left-sided colectomies can serve as safe training operations for less frequent, low anterior resections for rectal cancer is still under debate. Therefore, the aim of this study was to evaluate intra- and postoperative results of robotic-assisted laparoscopy (RAL) compared to laparoscopic (LSC) surgery in left-sided colectomies.

Methods Between June 2015 and December 2019, 683 patients undergoing minimally invasive left-sided colectomies in two Swiss, high-volume colorectal centers were included. Intra- and postoperative outcome parameters were collected and analyzed.

Results A total of 179 patients undergoing RAL and 504 patients undergoing LSC were analyzed. Baseline characteristics showed similar results. Intraoperative complications occurred in $0.6 \%$ of RAL and $2.0 \%$ of LSC patients $(p=0.193)$. Differences in postoperative complications graded Dindo $\geq 3$ were not statistically significant (RAL 3.9\% vs. LSC 6.3\%, $p=0.227$ ). Occurrence of anastomotic leakages showed no statistically significant difference [RAL $n=2(1.1 \%)$, LSC $n=8(1.6 \%)$, $p=0.653]$. Length of hospital stay was similar in both groups. Conversions to open surgery were significantly higher in the LSC group $(6.2 \%$ vs. $1.7 \%, p=0.018)$, while stoma formation was similar in both groups [RAL $n=1(0.6 \%)$, LSC $n=5$ $(1.0 \%), p=0.594]$. Operative time was longer in the RAL group (300 vs. $210.0 \mathrm{~min}, p<0.001$ ).

Conclusion Robotic-assisted, left-sided colectomies are safe and feasible compared to laparoscopic resections. Intra- and postoperative complications are similar in both groups. Most notably, the rate of anastomotic leakages is similar. Compared to laparoscopic resections, the analyzed robotic-assisted resections have longer operative times but less conversion rates. Further prospective studies are needed to confirm the safety of robotic-assisted, left-sided colectomies as training procedures for low anterior resections.
\end{abstract}

Keywords Laparoscopic surgery $\cdot$ Robotic-assisted surgery $\cdot$ Left-sided colectomies

Jörn-Markus Gass and Diana Daume shared first authorship and contributed equally to this work.

Fiorenzo Angehrn and Martin Bolli shared last authorship and contributed equally to this work.

Martin Bolli

martin.bolli@clarunis.ch

1 Department of General Surgery, Cantonal Hospital of Lucerne, Spitalstrasse, 6000 Lucerne, Switzerland

2 Department of Health Sciences and Medicine, University of Lucerne, Frohburgstrasse 3, 6002 Lucerne, Switzerland
Over the last few decades, minimally invasive surgery has gained rising popularity. With the adoption of laparoscopic techniques, several advantages concerning length of hospital stay, level of postoperative pain, blood loss, and reduction of postoperative complications as well as faster return to

3 Clarunis, Department of Visceral Surgery, University Centre for Gastrointestinal and Liver Diseases, St. Clara Hospital and University Hospital Basel, Kleinriehenstrasse 30, 4058 Basel, Switzerland

4 Department of Surgery, Regional Hospital of Lugano, Via Tesserete 46, 6900 Lugano, Switzerland 
normal activities could be demonstrated. Now even complex procedures can be performed with at least equal and noninferior results compared to the open technique [1-4]. These advantages have also been proven for oncological resections, demonstrating non-inferiority in regards to oncological outcomes $[5,6]$. The implementation of robotic-assisted systems took minimally invasive surgery to the next level. The Endowrist ${ }^{\mathrm{TM}}$ function, with its improvement in comfort and maneuverability, filtration of tremor and motion by the computer system, high-definition 3-dimensional binocular vision with the option of magnification, fluorescence, and finally, a stable platform with a surgeon operated camera, can even be regarded as a revolution and new dimension in surgery [7-9].

The main advantages of robotic-assisted surgery have been described in procedures with confined spaces like in rectal and esophageal surgery. Until now, the lack of evidence and the higher costs of the new technique have limited a more extensive adoption of the robotic-assisted systems $[10,11]$. Comparative studies between roboticassisted and laparoscopic techniques were able to show that robotic-assisted abdominal surgery is safe, feasible, and at least equivalent in regards to short-term outcomes $[12,13]$. Clinical results are encouraging: conversion rates to open surgery, length of hospital stay, return to normal activities and work as well as recovery time are comparable [14, 15]. On the other hand, skeptics claim higher costs, longer operative time due to docking and redocking and the rather long learning curve $[16,17]$. Concerning colorectal surgery, the learning curve is estimated to comprise 35 procedures. In general, low anterior resections for rectal cancer are performed less frequently than colonic resections. Left-sided colectomies are performed routinely for either benign diseases like diverticulitis and symptomatic diverticulosis or for colon cancer. Essential parts of the procedure are part of low anterior resections as well. Therefore, the question arises, if left-sided colectomies can be performed safely as robotic-assisted training procedures to prepare for low anterior rectal resections.

The aim of the present study was to analyze intra- and short-term postoperative outcomes in patients, who underwent left-sided colectomies with either the Da Vinci Si and $\mathrm{Xi}$ robotic systems or a laparoscopic technique and to establish left-sided colectomies as a training procedure for low anterior resections for rectal cancer.

\section{Materials and methods}

\section{Inclusion and exclusion criteria}

The present study was approved by the local ethics committee [Ethikkommission Nordwest- und Zentralschweiz (EKNZ), Project-ID 2020-02969].
All patients aged $\geq 18$ years requiring elective leftsided colectomy (left hemicolectomies, sigmoidectomies, or rectosigmoidectomies) with a minimally invasive approach [robotic-assisted laparoscopy (RAL) or laparoscopy (LSC)] between June 2015 and December 2019 were included in this study. Patients with benign diseases (e.g., chronic and recurrent diverticulitis, polyps that could not be resected endoscopically) as well as malignancies were included. Tumors graded T4 preoperatively were excluded because we prefer an open approach for large tumors with suspicion of organ infiltration. The retrospective analysis of prospectively collected data was performed at two high-volume, colorectal surgery units. RAL vs. LSC was chosen according to instrument availability and surgeons' preference, with no specific selection criteria. All patients were preoperatively informed about the surgical technique.

\section{Data collection}

Data were retrospectively obtained from written hospital records, electronic databases as well as pathology and radiology reports. Demographic data (age, sex, and BMI) as well as outcome parameters were extracted, including conversion to open surgery, intra- and postoperative complications (30-day-morbidity), operative time, diverting stoma formation, postoperative length of hospital stay (LOS), blood transfusions, postoperative length of intensive care unit (ICU) stay (LOI), reoperations, and discharge at home or to a rehabilitation center.

\section{Surgical technique}

In RAL, a medial to lateral approach was most frequently performed (in selected cases lateral to medial as well). In the LSC resected patients, whether a medial to lateral or vice versa approach was used depended on the senior surgeon. In most patients, the splenic flexure was mobilized and, in nearly all patients, even for benign diseases an oncologic resection with central ligation of inferior mesenteric artery and vein was performed. Linear and circular stapling devices were routinely used to perform anastomoses via the double-stapling technique. The da Vinci $\mathrm{Si}{ }^{\circledR}$ and $\mathrm{Xi}{ }^{\circledR}$ robotic platforms (Intuitive Surgical, Sunnyvale, CA, USA) were used. Only one surgeon has had experience in robotic surgery when the robotic colorectal surgery program was started. All surgeons have been proctored repetitively by experienced international robotic colorectal surgeons. 


\section{Statistical analysis}

Descriptive statistics were presented as absolute frequencies for categorical variables and median with interquartile ranges (IQR) for continuous variables. The comparison of dichotomous values was performed with the chi-squared test, while continuous variables between groups were compared with the Mann-Whitney $U$ test. Additionally, a propensity score matched (PSM) analysis with 1:2 ratio (RAL:LSC) was used to minimize the effect of confounders. Patients were matched according to age, sex, BMI, indication for surgery, and the da Vinci $\mathrm{Xi}{ }^{\circledR}$ or $\mathrm{Si}{ }^{\circledR}$ surgical system [18]. Two separate PSM analyses were performed for procedures during the learning curve or after having finished the learning curve. According to Parascandola et al., the learning curve for robotic- assisted, left-sided colectomies was estimated to be 35-45 operations [19]. Prolonged LOS was defined as longer than the overall mean value of 10 days. A $p$ value $<0.05$ was considered statistically significant. Statistical analysis was performed on MedCalc Statistical Software version 19.5.3 (MedCalc Software Ltd, Ostend, Belgium; https://www.medcalc.org; 2020).

\section{Results}

\section{Patient characteristics}

Between June 2015 and December 2019, a total of 683 patients were included. Patients underwent left-sided colonic resections with either RAL $(n=179,26.2 \%)$ or LSC $(n=504,73.8 \%)$. Mean age was $65.0(56.0-72.0)$ years in the RAL group and 64.0 (55.0-73.0) years in the LSC group $(p=0.957)$. A total of 289 (42.3\%) patients were male (RAL $40.1 \%$ vs. LSC $46.4 \%, p=0.201)$. The mean BMI in the
RAL group was $25.9(23.3-28.7) \mathrm{kg} / \mathrm{m}^{2}$ vs. $25.2(22.9-28.3)$ $\mathrm{kg} / \mathrm{m}^{2}$ in the LSC group $(p=0.169)$. Indication for surgery was a malignant tumor in $23.6 \%(n=161)$ of the patients (RAL $12.9 \%$ vs. LSC $27.4 \%, p<0.001$ ). The first PSM analysis served to identify homogeneous groups in terms of patients' characteristics, and 528 patients were selected (176 in the RAL and 352 in the LSC groups). The second PSM analysis was performed to also take into account the type of robotic platform (da Vinci $\mathrm{Xi}{ }^{\circledR}$ system) and the learning curve-related bias, resulting in 132 patients selected (44 in the RAL and 88 in the LSC groups). After propensity score matching, no difference in patients' characteristics was noted between the groups. Details are displayed in Table 1.

\section{Surgical outcomes}

Intraoperative complication rate was not statistically different between the two groups (RAL $0.6 \%$ vs. LSC $2.0 \%$, $p=0.193$ ). Among intraoperative complications, four cases of bowel injury, three cases of bleeding (one in the RAL group), two lesions of the bladder, one ureter injury and a severe hypotension after pneumoperitoneum occurred. The conversion rate to open surgery was instead significantly higher in the LSC group (1.7\% vs. $6.1 \%, p=0.018)$. The 34 conversions were caused by adhesions in 19 cases, bowel injury in 4 cases, bladder injury in 2 cases, hypotension after pneumoperitoneum induction in 1 case, bulky tumor mass in 4 cases, technical problems in anastomosis formation in 1 case, hemorrhage in 1 case, ureter injury in 1 case, and obesity in 1 case. The PSM analyses confirmed the statistically significant difference between the groups. After classification according to Clavien-Dindo, most complications were Grade I or II, while only 7 (3.9\%) patients in the RAL group and $32(6.3 \%)$ patients in the LSC group suffered from complications graded Clavien-Dindo $\geq \operatorname{III}(p=0.227)$. Ileus

Table 1 Patient characteristics

\begin{tabular}{|c|c|c|c|c|c|c|c|c|c|}
\hline \multirow[t]{2}{*}{ Variable } & \multicolumn{3}{|l|}{ Overall analysis } & \multicolumn{3}{|l|}{ PSM analysis } & \multicolumn{3}{|c|}{$\begin{array}{l}\text { PSM analysis without learning curve opera- } \\
\text { tions }\end{array}$} \\
\hline & $\operatorname{RAL}(n=179)$ & $\operatorname{LSC}(n=504)$ & $p$ & $\operatorname{RAL}(n=176)$ & $\operatorname{LSC}(n=352)$ & $p$ & $\operatorname{RAL}(n=44)$ & $\operatorname{LSC}(n=88)$ & $p$ \\
\hline Age, years (IQR) & $65.0(56.0-72.0)$ & $64.0(55.0-73.0)$ & 0.957 & $65.0(56.0-72.0)$ & $64.0(55.0-72.0)$ & 0.692 & $69.0(62.0-73.0)$ & $66.5(56.5-74.5)$ & 0.871 \\
\hline $\begin{array}{l}\text { BMI, } \mathrm{kg} / \mathrm{m}^{2} \\
\text { (IQR) }\end{array}$ & $25.9(23.3-28.7)$ & $25.2(22.9-28.3)$ & 0.174 & $25.9(23.3-28.7)$ & $25.2(22.9-28.5)$ & 0.308 & $29.2(27.6-33.2)$ & $29.2(27.6-33.2)$ & 0.209 \\
\hline Gender, male (\%) & 83 (46.4) & $206(40.9)$ & 0.201 & 82 (46.6) & $152(43.2)$ & 0.458 & $26(59.1)$ & $54(61.4)$ & 0.802 \\
\hline $\begin{array}{l}\text { Indication to sur- } \\
\text { gery/malignant } \\
\text { disease, } \mathrm{n}(\%)\end{array}$ & $23(12.9)$ & $138(27.4)$ & $<0.001$ & $22(12.5)$ & $57(16.2)$ & 0.262 & $7(15.9)$ & $15(17.0)$ & 0.869 \\
\hline
\end{tabular}

Values are expressed as absolute numbers with percentage in parentheses or median with interquartile range (IQR). $B M I$ body mass index; $S D$ standard deviation; $L S C$ laparoscopic resection; RAL robotic-assisted laparoscopic resection; PSM propensity score matched 
was graded Clavien-Dindo II except for 1 patient who was readmitted at day 18 and needed revisional surgery for adhesive small bowel obstruction. Surgical site infections were graded Clavien-Dindo III when the wound was opened bedside under local anesthesia. Again, after PSM analyses, no statistically significant differences could be demonstrated. Details are reported in Table 2.

Of note, no difference concerning anastomotic leakage rate could be found between laparoscopic and roboticassisted resections [RAL $n=2(1.1 \%)$ vs. LSC $n=8(1.6 \%)$, $p=0.653]$. Reoperations were necessary in $2.4 \%$ of the patients after robotic-assisted surgery and in $2.2 \%$ of the patients after laparoscopic procedures $(p=0.522)$.
Operative time was significantly longer in the RAL group [300 (250-323) vs. $210(180-260)$ minutes, $p<0.001$ ] , and this difference was also confirmed after PSM analyses. The frequency of stoma formation was similar in both groups $(0.6 \%$ vs. $1.0 \%, p=0.594)$. Details are reported in Table 3 .

The median length of ICU stay was similar in the RAL and LSC group [ $1(1-2)$ vs. 1 (1-2) days, $p=0.605]$, but, interestingly, the proportion of patients requiring ICU admission was higher in the RAL group [46 (25.7\%) vs. 81 (16.1\%) patients in the RAL and LSC group, respectively, $p=0.004]$. This difference was also confirmed in the first PSM analysis, including the learning curve. In the PSM analysis with exclusion of the learning curve procedures,

Table 2 Comparison of outcomes between patients undergoing RAL versus LSC

\begin{tabular}{|c|c|c|c|c|c|c|c|c|c|}
\hline \multirow[t]{2}{*}{ Variable } & \multicolumn{3}{|l|}{ Overall analysis } & \multicolumn{3}{|l|}{ PSM analysis } & \multicolumn{3}{|c|}{$\begin{array}{l}\text { PSM analysis without learning curve } \\
\text { operations }\end{array}$} \\
\hline & $\operatorname{RAL}(n=179)$ & $\operatorname{LSC}(n=504)$ & $p$ & $\operatorname{RAL}(n=176)$ & $\operatorname{LSC}(n=352)$ & $p$ & RAL $(n=44)$ & $\operatorname{LSC}(n=88)$ & $p$ \\
\hline $\begin{array}{l}\text { Intraoperative } \\
\text { complica- } \\
\text { tions, } n(\%)\end{array}$ & $1(0.6)$ & $10(2.0)$ & 0.193 & $1(0.6)$ & $8(2.3)$ & 0.154 & 0 & $3(3.4)$ & 0.217 \\
\hline $\begin{array}{l}\text { Operative } \\
\text { time, min } \\
\text { (IQR) }\end{array}$ & $300(250-323)$ & $210(180-260)$ & $<0.001$ & $300(250-325)$ & $210(180-260)$ & $<0.001$ & $292(258-323)$ & $214(180-256)$ & $<0.001$ \\
\hline $\begin{array}{l}\text { Conversion } \\
\text { to open sur- } \\
\text { gery, } n(\%)\end{array}$ & $3(1.7)$ & $31(6.2)$ & 0.018 & $3(1.7)$ & $20(5.7)$ & 0.035 & 0 & $7(8.0)$ & 0.050 \\
\hline $\begin{array}{l}\text { Stoma forma- } \\
\text { tion, } n(\%)\end{array}$ & $1(0.6)$ & $5(1.0)$ & 0.594 & $1(0.6)$ & $2(0.6)$ & 1.000 & 0 & 0 & 1.000 \\
\hline $\begin{array}{l}\text { ICU required, } \\
n(\%)\end{array}$ & $46(25.7)$ & $81(16.1)$ & 0.004 & $46(26.1)$ & $47(13.4)$ & $<0.001$ & $15(34.1)$ & 19 (21.6) & 0.123 \\
\hline $\begin{array}{l}\text { ICU stay, days } \\
\text { (IQR) }\end{array}$ & $1(1-2)$ & $1(1-2)$ & 0.605 & $1(1-2)$ & $1(1-2)$ & 0.884 & $1(1-3)$ & $1(1-2)$ & 0.348 \\
\hline $\begin{array}{l}\text { Blood transfu- } \\
\text { sions, } n(\%)\end{array}$ & $5(2.8)$ & $11(2.2)$ & 0.215 & $5(2.8)$ & $6(1.7)$ & 0.389 & $2(4.5)$ & 0 & 0.045 \\
\hline \multicolumn{10}{|l|}{$\begin{array}{l}\text { Postoperative } \\
\text { complica- } \\
\text { tions }\end{array}$} \\
\hline $\begin{array}{l}\text { - Clavien- } \\
\text { Dindo } \geq \mathrm{III} \\
n(\%)\end{array}$ & $7(3.9)$ & $32(6.3)$ & 0.227 & $7(4.0)$ & $23(6.5)$ & 0.232 & $1(2.3)$ & $5(5.7)$ & 0.377 \\
\hline $\begin{array}{l}\text { - Anas- } \\
\text { tomotic } \\
\text { leakage, } n \\
(\%)\end{array}$ & $2(1.1)$ & $8(1.6)$ & 0.653 & $2(1.1)$ & $5(1.4)$ & 0.788 & 0 & $3(3.4)$ & 0.217 \\
\hline $\begin{array}{l}\text { - Length of } \\
\text { hospital } \\
\text { stay, days } \\
\text { (IQR) }\end{array}$ & $9(8-11)$ & $9(7-11)$ & 0.328 & $9(8-11)$ & $9(7-11)$ & 0.108 & $10(8-11)$ & $9(8-11)$ & 0.547 \\
\hline $\begin{array}{l}\text { Reoperations, } \\
n(\%)\end{array}$ & $4(222)$ & $16(3.2)$ & 0.522 & $4(2.3)$ & $11(3.1)$ & 0.579 & 0 & $3(3.4)$ & 0.217 \\
\hline $\begin{array}{l}\text { Discharged } \\
\text { home, } n(\%)\end{array}$ & $168(93.8)$ & $464(92.1)$ & 0.434 & 165 (93.7) & $328(93.2)$ & 0.805 & $41(93.2)$ & $84(95.5)$ & 0.584 \\
\hline
\end{tabular}

Values are expressed as absolute numbers with percentage in parentheses or median with interquartile range (IQR). SD standard deviation; $L S C$ laparoscopic resection; $R A L$ robotic-assisted laparoscopic resection; $I C U$ intensive care unit 
Table 3 Postoperative complications

\begin{tabular}{lll}
\hline Postoperative complications & RAL $(n=179)$ & LSC $(n=504)$ \\
\hline Clavien-Dindo $\geq$ III & & \\
·Anastomotic leakage, $n(\%)$ & $2(1.1)$ & $8(1.6)$ \\
-Surgical site infection superficial, & $2(1.1)$ & $1(0.2)$ \\
$\quad n(\%)$ & & \\
-Bowel perforation, $n(\%)$ & $1(0.6)$ & $2(0.4)$ \\
·Bile duct injury, $n(\%)$ & $1(0.6)$ & 0 \\
-Surgical site infection deep, $n(\%)$ & $1(0.6)$ & 0 \\
-Anastomotic bleeding, $n(\%)$ & 0 & $7(1.4)$ \\
-Cardiovascular, $n(\%)$ & 0 & $3(0.6)$ \\
-Ileus, $n(\%)$ & 0 & $3(0.6)$ \\
-Trocar site hernia, $n(\%)$ & 0 & $3(0.6)$ \\
·Pneumonia, $n(\%)$ & 0 & $2(0.4)$ \\
·Presence of foreign body & 0 & $2(0.4)$ \\
-Intraabdominal hematoma, $n(\%)$ & 0 & $1(0.2)$ \\
\hline
\end{tabular}

Values are expressed as absolute numbers with percentage in parentheses

no statistically significant difference could be demonstrated, probably because of the reduced sample size.

Length of hospital stay was similar in both groups [9 (8-11) vs. 9 (7-11) days in the RAL and LSC groups, respectively, $p=0.328$ ]. Regardless of the type of surgery performed, most patients could be discharged home without the need for further rehabilitation or alternative health care facilities $(93.8 \%$ vs. $92.1 \%$ in the RAL and LSC groups, respectively, $p=0.434$ ).

To detect differences in outcome parameters for benign and malignant lesions, a third PSM analysis was performed. As expected, patients in the subgroup for malignancies were older than in the general analysis and male sex was more prevalent. Intra- and postoperative outcomes were similar to the overall analysis and no noteworthy differences could be found.

\section{Discussion}

This analysis represents the data of two high-volume colorectal centers in Switzerland. A total of 683 patients (179 RAL and 504 LSC) were included, and data were analyzed for several outcome parameters.

Complications were classified according to Clavien-Dindo, complications graded higher or equal III were not statistically significantly different $(7.7 \%$ RAL vs. $11.2 \%$ LSC, $p=0.160$ ) in both cohorts. These results are comparable with a study from Dolejs et al. in 2017 [20]. The team reviewed a large, nationwide dataset of patients undergoing colectomies with primary anastomosis between 2012 and 2014 and sub-classified patients into different kinds of colorectal resections. Unfortunately, morbidity was not classified according to Clavien-Dindo but into two categories: "overall morbidity" and "serious morbidity". Serious complication rate was $9 \%$ for patients undergoing left-sided laparoscopic resections compared to $7.2 \%$ for robotic-assisted resections, and no statistically significant difference could be demonstrated $(p=0.190)$. Strikingly, in our patient population, the proportion of anastomotic leakage and hemorrhage was higher in the laparoscopic group though not statistically significant. This remains unexplained since anastomotic technique and stapling devices were identical in both cohorts.

Concerning stoma formation one patient in the roboticassisted group needed a stoma vs. five patients in the laparoscopic group $(0.6 \%$ vs. $1.0 \%, p=0.594)$, this difference failed to be statistically significant. Elliott et al. compared robotic-assisted vs. laparoscopic resections for sigmoid diverticulitis with fistula and found, in contradiction to our results, a higher rate of stoma formation in the RAL than in the LSC group [ $n=2(18 \%)$ vs. $n=0(0 \%) p=0.048]$ [21]. An explanation for the higher rate of stoma formation in the study by Elliott might be the newer technique of robotic-assisted resections and the wish to "protect" the surgical result or simply the small sample size and heterogenous patient cohort.

Conversion rate is a vital outcome parameter for surgical quality. After conversion to open surgery, patients have a longer hospital stay and an increased risk of developing postoperative complications as well as poorer oncological outcomes [22]. Furthermore, institutions and payers claim the additional costs of converted surgical procedures and longer hospital stay for the healthcare system [23]. Conversion rate in our analysis was significantly lower in in the RAL group compared to the LSC group (1.7\% RAL vs. 6.1\% LSC, $p=0.018$ ). In 2016, Zhang published a meta-analysis comparing clinicopathological outcomes of robotic-assisted and laparoscopic colorectal surgery for cancer. Twenty-four studies with a total of 3318 patients were included and, in agreement with our data, a significantly lower conversion rate in the RAL group could be demonstrated [24]. The reason for the lower conversion rate in robotic-assisted resections might be the multiple technical advantages making it easier to cope with intraoperative difficulties like adhesions, narrow pelvis, or overweight patients. Furthermore, especially in the beginning of the era of robotic-assisted surgery, most surgeons performing robotic-assisted operations were experienced laparoscopic surgeons as well, which might have led to lower conversion rates, too. Finally, for a newly introduced technique, a selection bias for the straight-forward and easier cases should probably be considered as well.

Operative time was significantly longer for the RAL group compared to the LSC group. Several robotic-assisted 
surgery studies in various specialties confer to this result. In 2016, Ferrara et al. from Siena reported very similar operative times for a population of patients with any kind of colorectal surgery (RAL 293.6 vs. LSC $223.0 \mathrm{~min}$ ) [25]. These findings are in accordance with a study by Raskin et al. from 2019. For patients with resections for diverticular disease operating room times were statistically significantly longer for the robotic-assisted group compared with the open group ( $256.5 \pm 75.2 \mathrm{~min}$. vs. $197.6 \pm 74.3 \mathrm{~min}$.) and for the robotic-assisted group compared with the laparoscopic group (254.4 $\pm 74.8 \mathrm{~min}$. vs. $212.2 \pm 75.0 \mathrm{~min}$.) [26-29]. In our experience, a standardization of docking steps and repetitive training with identical teams are key points to reduce operative time. A confounding factor for the longer operative time might be the use of the da Vinci $\mathrm{Si}{ }^{\circledR}$ platform for a relevant number of cases $\left[n=29(16.2 \%)\right.$ da Vinci $\mathrm{Si}{ }^{\circledR}$ vs. $n=150(83,8 \%)$ da Vinci $\left.\mathrm{Xi}{ }^{\circledR}\right]$. This assumption is supported by a study from Hill and McCormick, which showed a significant reduction of operative times in, for example, sigmoidectomies when comparing the da Vinci $\mathrm{Si}{ }^{\circledR}$ with the da Vinci Xi ${ }^{\circledR}$ platform (235 min. vs. 162 min., $p=0.0001$ ) [30]. Surprisingly, in our study, the mean operative time for the $\mathrm{Si}{ }^{\circledR}$ group was $290.96 \mathrm{~min}$. $( \pm 68.99)$, whereas the mean operative time for the da Vinci $\mathrm{Xi}{ }^{\circledR}$ procedures was 296.91 min. $( \pm 57.22)$. In the center with the da Vinci Xi ${ }^{\circledR}$ platform, five surgeons performed robotic-assisted operations, which means more patients were operated during the learning curve phase. For capacity reasons, after completing the learning curve, only demanding cases were scheduled for the robotic-assisted approach. This might explain the longer operative times for the da Vinci Xi® surgical system.

Our data analysis has shown a similar hospital stay for patients with robotic-assisted resections (10.3 days RAL vs. 9.9 days LSC, $p=0.434)$. This result is corroborated by a meta-analysis from Trin and coworkers. They analyzed and reviewed 14 studies on colorectal laparoscopic vs. roboticassisted resections. In all studies, length of postoperative hospital stay was assessed; statistical analysis yielded no difference between the two approaches as well [11]. As a matter of fact, length of hospital stay is an increasingly important outcome parameter, since it has significant implications on procedure associated costs.

Over the last few years, more and more hospitals have started ERAS programs for colorectal surgery. In both colorectal centers ERAS programs have now been implemented. Nevertheless, data acquisition of the present study was completely finished before starting ERAS programs. This might explain the rather long hospital stay of our patients compared to current literature. The proportion of patients requiring ICU admission (comprising ICU, intermediate care unit, and recovery room) postoperatively was higher in the RAL group [46 (25.7\%) vs. $81(16.1 \%)$ patients in the RAL and LSC group, respectively, $p=0.004]$. This result can be attributed to the initial policy of transferring every patient to the ICU for safety reasons in the beginning of the implementation of the robotic-assisted surgery program. In the further course, only complex resections which indeed needed ICU treatment were scheduled for robotic-assisted resections.

The present study has some limitations. The study character is retrospective and has no randomization. In a retrospective study design, data quality depends on correct acquisition and completeness of intraoperative details and documentation of the postoperative course. There may have been a selection bias between the RAL and the LSC groups, though multivariate analyses tend to compensate for this issue. Another confounder might be the learning curve and the unequal experience in minimally invasive techniques of the surgeons, which could contribute to longer operative times in the RAL group. Furthermore, the use of two different generations of robotic-assisted platforms in the two institutions might reduce comparability of the data as well. However, such potential biases related to selection of patients, type of da Vinci ${ }^{\circledR}$ robotic platform and the learning curve effect were addressed with a PSM analysis, which showed no noteworthy differences compared to the main analysis.

\section{Conclusion}

Robotic-assisted laparoscopic resections for left-sided colectomies are safe and feasible and can therefore serve as training procedures for robotic-assisted low anterior resections. Intra- and postoperative complications are similar in both the RAL and LSC groups. Most notably, the rate of anastomotic leakages is similar. Compared to laparoscopic resections, the analyzed robotic-assisted resections have longer operative times but less need to conversion. Future prospective randomized trials with the latest da Vinci Xi® surgical system should be performed to mitigate confounders of the present study and to further establish the use of robotic platforms for left-sided colectomies.

Acknowledgements We thank Nicole Viggiano for language review.

Funding Open access funding provided by University of Basel. No grant support or other funds were received for this work.

\section{Declarations}

Disclosures Jörn-Markus Gass, Diana Daume, Romano Schneider, Daniel Steinemann, Francesco Mongelli, Andreas Scheiwiller, Lana Fourie, Beatrice Kern, Markus von Flüe, Jürg Metzger, Fiorenzo Angehrn, Martin Bolli have no conflicts of interest or financial ties to disclose. 
Ethical approval The Ethikkommission Nordwest- und Zentralschweiz (EKNZ) (Swiss Ethics Committee) approved this study, Project-ID 2020-02969.

Open Access This article is licensed under a Creative Commons Attribution 4.0 International License, which permits use, sharing, adaptation, distribution and reproduction in any medium or format, as long as you give appropriate credit to the original author(s) and the source, provide a link to the Creative Commons licence, and indicate if changes were made. The images or other third party material in this article are included in the article's Creative Commons licence, unless indicated otherwise in a credit line to the material. If material is not included in the article's Creative Commons licence and your intended use is not permitted by statutory regulation or exceeds the permitted use, you will need to obtain permission directly from the copyright holder. To view a copy of this licence, visit http://creativecommons.org/licenses/by/4.0/.

\section{References}

1. Keller DS, Delaney CP, Hashemi L, Haas EM (2016) A national evaluation of clinical and economic outcomes in open versus laparoscopic colorectal surgery. Surg Endosc 30:4220-4228

2. Siddiqui MR, Sajid MS, Qureshi S, Cheek E, Baig MK (2010) Elective laparoscopic sigmoid resection for diverticular disease has fewer complications than conventional surgery: a meta-analysis. Am J Surg 200:144-161

3. Kakarla VR, Nurkin SJ, Sharma S, Ruiz DE, Tiszenkel H (2012) Elective laparoscopic versus open colectomy for diverticulosis: an analysis of ACS-NSQIP database. Surg Endosc 26:1837-1842

4. Guller U, Jain N, Hervey S, Purves H, Pietrobon R (2003) Laparoscopic vs open colectomy: outcomes comparison based on large nationwide databases. Arch Surg 138:1179-1186

5. Fleshman J, Branda ME, Sargent DJ, Boller AM, George VV, Abbas MA, Peters WR Jr, Maun DC, Chang GJ, Herline A, Fichera A, Mutch MG, Wexner SD, Whiteford MH, Marks J, Birnbaum E, Margolin DA, Larson DW, Marcello PW, Posner MC, Read TE, Monson JRT, Wren SM, Pisters PWT, Nelson H (2019) Disease-free survival and local recurrence for laparoscopic resection compared with open resection of stage II to III rectal cancer: follow-up results of the ACOSOG Z6051 randomized controlled trial. Ann Surg 269:589-595

6. Stevenson ARL, Solomon MJ, Brown CSB, Lumley JW, Hewett P, Clouston AD, Gebski VJ, Wilson K, Hague W, Simes J, Australasian Gastro-Intestinal Trials Group Ai (2019) Disease-free survival and local recurrence after laparoscopic-assisted resection or open resection for rectal cancer: the Australasian laparoscopic cancer of the rectum randomized clinical trial. Ann Surg 269:596-602

7. Esen E, Aytac E, Ozben V, Bas M, Bilgin IA, Aghayeva A, Baca B, Hamzaoglu I, Karahasanoglu T (2019) Adoption of robotic technology in Turkey: a nationwide analysis on caseload and platform used. Int J Med Robot 15:e1962

8. Bilgin IA, Bas M, Benlice C, Esen E, Ozben V, Aytac E, Baca B, Hamzaoglu I, Karahasanoglu T (2020) Totally laparoscopic and totally robotic surgery in patients with left-sided colonic diverticulitis. Int J Med Robot 16:e2068

9. Casillas MA Jr, Leichtle SW, Wahl WL, Lampman RM, Welch KB, Wellock T, Madden EB, Cleary RK (2014) Improved perioperative and short-term outcomes of robotic versus conventional laparoscopic colorectal operations. Am J Surg 208:33-40

10. Yang TX, Chua TC (2013) Single-incision laparoscopic colectomy versus conventional multiport laparoscopic colectomy: a metaanalysis of comparative studies. Int J Colorectal Dis 28:89-101
11. Trinh BB, Jackson NR, Hauch AT, Hu T, Kandil E (2014) Robotic versus laparoscopic colorectal surgery. JSLS. https://doi.org/10. 4293/JSLS.2014.00187

12. Kim JY, Kim NK, Lee KY, Hur H, Min BS, Kim JH (2012) A comparative study of voiding and sexual function after total mesorectal excision with autonomic nerve preservation for rectal cancer: laparoscopic versus robotic surgery. Ann Surg Oncol 19:2485-2493

13. Rawlings AL, Woodland JH, Vegunta RK, Crawford DL (2007) Robotic versus laparoscopic colectomy. Surg Endosc 21:1701-1708

14. Baek SJ, Al-Asari S, Jeong DH, Hur H, Min BS, Baik SH, Kim NK (2013) Robotic versus laparoscopic coloanal anastomosis with or without intersphincteric resection for rectal cancer. Surg Endosc 27:4157-4163

15. Alasari S, Min BS (2012) Robotic colorectal surgery: a systematic review. ISRN Surg 2012:293894

16. Davis BR, Yoo AC, Moore M, Gunnarsson C (2014) Roboticassisted versus laparoscopic colectomy: cost and clinical outcomes. JSLS 18:211-224

17. Al-Mazrou AM, Baser O, Kiran RP (2018) Propensity scorematched analysis of clinical and financial outcomes after robotic and laparoscopic colorectal resection. J Gastrointest Surg 22:1043-1051

18. Haukoos JS, Lewis RJ (2015) The propensity score. JAMA 314:1637-1638

19. Parascandola SA, Horsey ML, Hota S, Paull JO, Graham A, Pudalov N, Smith S, Amdur R, Obias V (2020) The robotic colorectal experience: an outcomes and learning curve analysis of 502 patients. Colorectal Dis 23:226-236

20. Dolejs SC, Waters JA, Ceppa EP, Zarzaur BL (2017) Laparoscopic versus robotic colectomy: a national surgical quality improvement project analysis. Surg Endosc 31:2387-2396

21. Elliott PA, McLemore EC, Abbass MA, Abbas MA (2015) Robotic versus laparoscopic resection for sigmoid diverticulitis with fistula. J Robot Surg 9:137-142

22. European Society of Coloproctology collaborating groups (2018) The impact of conversion on the risk of major complication following laparoscopic colonic surgery: an international, multicentre prospective audit. Colorectal Dis 20(Suppl 6):69-89

23. Cleary RK, Mullard AJ, Ferraro J, Regenbogen SE (2018) The cost of conversion in robotic and laparoscopic colorectal surgery. Surg Endosc 32:1515-1524

24. Zhang X, Wei Z, Bie M, Peng X, Chen C (2016) Robot-assisted versus laparoscopic-assisted surgery for colorectal cancer: a metaanalysis. Surg Endosc 30:5601-5614

25. Ferrara F, Piagnerelli R, Scheiterle M, Di Mare G, Gnoni P, Marrelli D, Roviello F (2016) Laparoscopy versus robotic surgery for colorectal cancer: a single-center initial experience. Surg Innov 23:374-380

26. Rashidi L, Neighorn C, Bastawrous A (2017) Outcome comparisons between high-volume robotic and laparoscopic surgeons in a large healthcare system. Am J Surg 213:901-905

27. Raskin ER, Keller DS, Gorrepati ML, Akiel-Fu S, Mehendale S, Cleary RK (2019) Propensity-matched analysis of sigmoidectomies for diverticular disease. JSLS. https://doi.org/10.4293/JSLS. 2018.00073

28. Fung AK, Aly EH (2013) Robotic colonic surgery: is it advisable to commence a new learning curve? Dis Colon Rectum 56:786-796

29. Gorgun E, Aytac E, Gurland B, Costedio MM (2015) Casematched comparison of robotic versus laparoscopic colorectal surgery: initial institutional experience. Surg Laparosc Endosc Percutan Tech 25:e148-151

30. Hill A, McCormick J (2020) In experienced hands, does the robotic platform impact operative efficiency? Comparison of the 
da Vinci Si versus Xi robot in colorectal surgery. J Robot Surg 14:789-792
Publisher's Note Springer Nature remains neutral with regard to jurisdictional claims in published maps and institutional affiliations. 